\title{
Molecular Orientation Effect of Heat-Sealed PP Film on Peel Strength and Structure
}

\author{
Kazushi Yamada ${ }^{1}$, Ken Miyata ${ }^{2}$, Reiichi Konishi ${ }^{3}$, Kiyomi Okada ${ }^{4}$, Tetsuya Tsujii ${ }^{4}$ \\ ${ }^{1}$ Kyoto Institute of Technology, Kyoto, Japan \\ ${ }^{2}$ Yamagata University, Yamagata, Japan \\ ${ }^{3}$ Nakamoto Packs Co., Ltd., Osaka, Japan \\ ${ }^{4}$ PerkinElmer Japan Co., Ltd., Osaka, Japan \\ Email: ${ }^{*} k a z u s h i @ k i t . a c . j p$
}

Received 22 September 2015; accepted 2 November 2015; published 5 November 2015

Copyright (C) 2015 by authors and Scientific Research Publishing Inc.

This work is licensed under the Creative Commons Attribution International License (CC BY). http://creativecommons.org/licenses/by/4.0/

(c) (i) Open Access

\begin{abstract}
Heat sealing properties are optimized by controlling temperature, pressure and dwell time, while film strength depends on the drawn ratio and the molecular orientation of the film. However, heat seal strength of polymer films with high drawn ratio shows lower peel strength, because the adhesion of films needs a higher heat sealing energy for molecular orientation relaxation at heat sealing. In the present study, polypropylene films with a drawn ratio of $1.0 \times, 1.5 \times$, and $2.5 \times$ are heat sealed by using the heat sealing technique. The heat sealing condition is set to heat sealing time $1.0 \mathrm{~s}$, sealing pressure $0.2 \mathrm{MPa}$, and heat sealing temperature $145^{\circ} \mathrm{C}$. The effect of drawn ratio and stabilization temperature of PP films for peel strength are investigated using T-Peel test, DSC, FT-IR, and Raman spectroscopy. As a result, it is found that the peel strength is decreased with increasing the drawn ratio and stabilization temperature of PP films. The difference of $\Delta H$ and melting point from the result of DSC measurement are exhibited for $1.5 \times$ drawn ratio film as compared with $2.5 \times$ one. In addition, FT-IR imaging and Raman line mapping reveal the influence and variation of high order structure for heat sealed parts of the drawn PP films.
\end{abstract}

Keywords

Uniaxially-Extended Polypropylene, Molecular Orientation, Heat Sealing

\section{Introduction}

In recent years, plastic bags with heat-sealing are widely used in food packages, such as snack, retort pouch,

*Corresponding author.

How to cite this paper: Yamada, K., Miyata, K., Konishi, R., Okada, K. and Tsujii, T. (2015) Molecular Orientation Effect of Heat-Sealed PP Film on Peel Strength and Structure. Advances in Materials Physics and Chemistry, 5, 439-446.

http://dx.doi.org/10.4236/ampc.2015.511044 
frozen food, and so on. Heat seal technology is a very important technique for packaging industries because of keeping a long shelf life for food. Basically, there are two typical films, which are generally used, including laminated films and homo films. Heat seal is carried out by fusing the polymers through the application of heat and pressure. The initial pressure makes closely contact with both of film surfaces. Then adhesion is promoted by applying heat and pressure from the outside of films. The important factors to obtain great heat seal properties include heat sealing temperature, heat seal pressure, heat seal time and dwell time for a cool down after heat sealing. Many researchers have investigated about heat sealing time, temperature, and pressure to evaluate the mechanical properties of heat sealed parts of plastic bags [1]-[9].

On the other hand, film strength depends on the drawn ratio and molecular orientation of the film. The packaging film with high drawn ratio can be generally used for plastic bags which are required for high tensile strength, whereas the plastic film with a low drawn ratio can be made available for sealant layer, that is, OPP/ CPP laminated film. However, to use chemical adhesion bond for laminated films is undesirable from a viewpoint of environmental load, while thermal laminated films or homo films are desirable as plastic bags in future. The heat sealing ability of higher molecular orientation films is poor due to loss of the heat sealing energy for the relaxation of oriented molecules in polymer films. Accordingly, it is very important to understand the relationship between heat sealing conditions, molecular orientation, higher order structure, stabilization temperature in polymer films in order to evaluate the difference of mechanical properties in heat sealed parts.

In this research, we use homo-polymer film specimens with the different drawn ratio in order to evaluate the effect of molecular orientation on heat sealed properties. The films are heat sealed with heat bar sealing machine at heat sealing condition, which is heat sealing time $1.0 \mathrm{~s}$, heat sealing pressure $0.2 \mathrm{MPa}$ and heat sealing temperature $145^{\circ} \mathrm{C}$. The difference of higher order structure of the films is discussed on the basis of results of micro-Raman spectroscopy, FT-IR spectroscopy, DSC and tensile test.

\section{Experimental}

\subsection{Materials}

In this study, cast polypropylene (CPP) film (TOYOBO, PYLEN FILM-CT, P1011, Japan) was used as a base film. This CPP film was unidirectionally drawn at 1.0, 1.5, 2.5 times by uniaxial drawn machine (Nakamoto Packs Co., Ltd., Japan). At that time, these films were annealed at $80^{\circ} \mathrm{C}, 100^{\circ} \mathrm{C}, 120^{\circ} \mathrm{C}$ to stabilize molecular orientation and drawn film. The drawn film conditions then will be referred as $1.0 \times, 1.5 \times$, and $2.5 \times$, respectively.

\subsection{Heat Sealing}

Figure 1 shows a schematic diagram of heat sealing method in this experiment. The uniaxial drawn and undrawn films were placed in a bar type heat-sealing machine (Heat seal Tester, Sangyo Co., Ltd, Japan). The heat seal pressure was kept constantly at $0.2 \mathrm{MPa}$. The heat sealing time was 1.0 second. The heat sealing temperature was set to $145^{\circ} \mathrm{C}$.

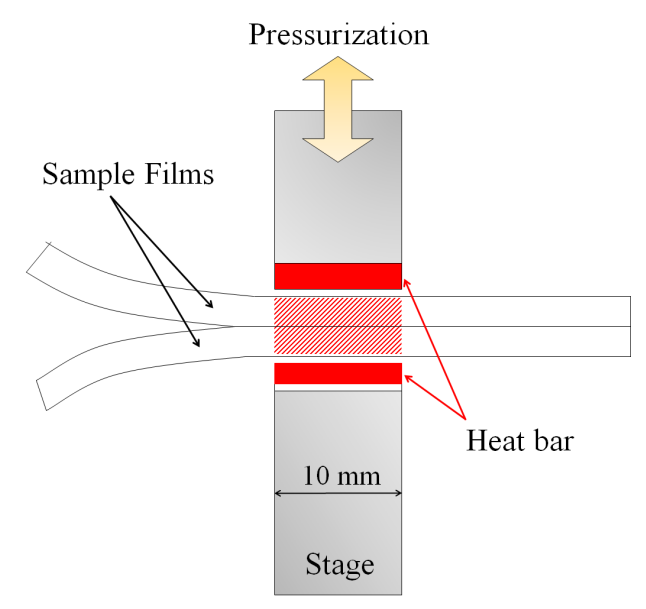

Figure 1. Schematic illustration of heat sealing process. 


\subsection{Peel Test}

In order to examine the mechanical properties of the heat sealed part, a T-peel test was carried out with test pieces of $15 \mathrm{~mm}$ wide and $100 \mathrm{~mm}$ long. A schematic draw of the heat sealed specimen is shown in Figure 2. The peel test was performed at $300 \mathrm{~mm} / \mathrm{min}$ by using an INSTRON universal testing machine (INSTRON 4466) at $20^{\circ} \mathrm{C}$. The span length was $50 \mathrm{~mm}$.

\subsection{DSC Measurement}

To examine the thermal properties of drawn sample films, a Differential Scanning Calorimeter (DSC) (Perkin-Elmer DSC, Pyris1) was utilized in the range of $40^{\circ} \mathrm{C}$ to $250^{\circ} \mathrm{C}$ at a heating rate of $20^{\circ} \mathrm{C} / \mathrm{min}$ under a nitrogen gas purge. The temperature and heat of transition obtained by the instrument were calibrated with indium and zinc standards before the measurements.

\subsection{Microscopic FT-IR Measurement}

Heat sealed part of specimens were mapping by microscopic FT-IR (Frontier-Spotlight 400: Perkin Elmer, Japan) to evaluate the crystallinity and the orientation of heat sealed parts with and without heat sealing. Mapping mode was transmittance imaging method. Wave resolution was $4 \mathrm{~cm}^{-1}$ with 2 scans. Pixel size was set to $25 \mu \mathrm{m}$.

\subsection{Microscopic Raman Spectroscopy}

Raman spectra have been measured with the micro-Raman backscattering geometry. The Raman spectra were excited with the linearly polarized $633 \mathrm{~nm}$ line of He-Ne laser (LabRAM HR-800: HORIBA Co., Ltd., Japan). The excitation beam was directed to the sample compartment of a properly modulated metallurgical microscope (Olympus BX-41). The microscope was used for the delivery of the excitation laser beam on the sample and the collection of the backscattered light through a beam splitter with objective lens adapted to the aperture of the microscope. Exposed time was set to1.0 s. The number of scan was set to 5 times.

\section{Results and Discussion}

\subsection{Effect of Stabilization Temperature of Each Drawn Film on Peel Strength}

Figure 3 shows the peel strength of drawn film specimens at various stabilization temperatures. Peel strength of cast PP film was about $10 \mathrm{~N}$. All of peel strengths for the drawn films indicated lower than that of cast PP film. The peel strength was decreased with increasing the drawn ratio for the PP film, while the peel strength was decreased with increasing the stabilization temperature for $1.0 \times$ and $2.5 \times$ drawn films although the peel strength of $1.5 \times$ drawn film was slightly increased with increasing the stabilization temperature. The peel strength for $1.5 \times$ drawn film showed around $3 \mathrm{~N} / 15 \mathrm{~mm}$, while the peel strength for $2.5 \times$ drawn film showed about only 1

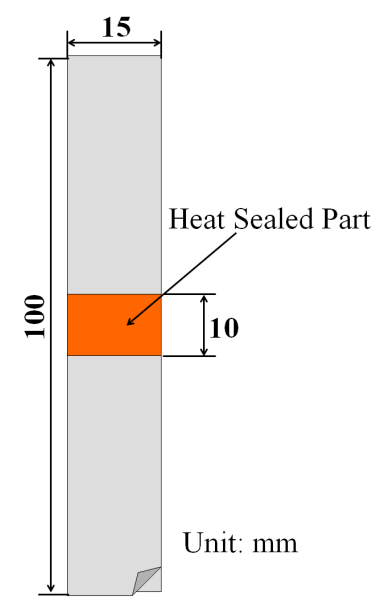

Figure 2. Schematic illustration of a specimen for peel test. 


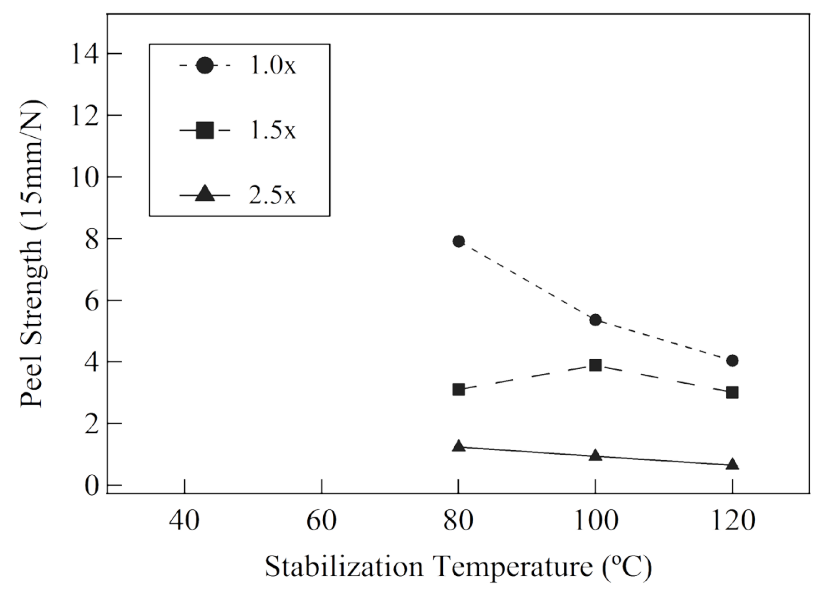

Figure 3. Peel strength of drawn film specimens for various stabilization temperatures at a heat sealed temperature of $145^{\circ} \mathrm{C}$.

$\mathrm{N} / 15 \mathrm{~mm}$, and the strength reduced to approximately $30 \%$. This is caused by the high molecular orientation degree in PP film as compared with low drawn ratio films such as $1.0 \times$ and $1.5 \times$. As a result, it was hard to heat seal for $2.5 \times$ drawn film. Thus, it is considered that there is a linear relationship between drawn ratio and peel strength, that is, depending on the orientation degree of PP molecules in the films.

\subsection{DSC Measurement}

We tried to perform DSC measurement in order to evaluate the change in crystallinity of higher order structure at heat sealed part of the PP drawn films. Figure 4(a) and Figure 4(b) shows the typically DSC curves of CPP film and $2.5 \times$ drawn PP film at $145^{\circ} \mathrm{C}$ heat sealing temperature, respectively. Melting temperature and melting enthalpy $(\Delta \mathrm{H})$ value of the 1 st and the 2 nd heating thermogram of CPP film are similar, while melting point of the 1st heating thermogram of $2.5 \times$ drawn film exhibited higher value as compared with the 2nd one. This difference depends on the drawn ratio of PP film, which influenced on differences in the molecular orientation of PP films. $\Delta \mathrm{H}$ values of the films and heat sealed films at each heat sealing condition are shown in Figure 5. It was found that $\Delta \mathrm{H}$ of non-heat sealed film was lower than heat sealed part due to a higher crystallinity of the heat sealed part as compared with the non-heat sealed part. In addition, $\Delta \mathrm{H}$ of higher drawn ratio was lower than that of lower drawn ratio. It was attributed to the crystallization of the film after heat sealed. It can be considered that $\Delta \mathrm{H}$ of higher drawn ratio film becomes low due to the energy waste to make it relaxation of the molecular orientation in PP films. Accordingly, these results will support the change in the secondary order structure of PP films. However, in the results of DSC measurement, it is very difficult to obtain the precise and information on secondary structure change in the edge area of heat sealed part. Hence, we applied the micro FT-IR mapping for heat sealed edge part of PP film for better understanding.

\subsection{Microscopic FT-IR Measurement}

Figure 6 shows a typical FT-IR spectrum of PP film. Generally, the $998 \mathrm{~cm}^{-1}$ and $841 \mathrm{~cm}^{-1}$ bands are associated with long repeating monomer units in the crystalline $3_{1}$ helix of PP. The short helix segments are associated with the $972 \mathrm{~cm}^{-1}$ band of the FT-IR spectrum. There is a linear correlation between the intensities of the $998 \mathrm{~cm}^{-1}$ and $841 \mathrm{~cm}^{-1}$ bands and the density of PP as a measure of its crystallinity. Therefore, the crystallinity of PP can be determined by the ratio of the $998 \mathrm{~cm}^{-1}$ and $972 \mathrm{~cm}^{-1}$ absorption bands [10] [11]. Figure 7 and Figure 8 shows the CCD optical images and illustrate the FT-IR mapping images of PP film of heat sealed edge part. These mapping images were normalized at $972 \mathrm{~cm}^{-1}$ and imaged the peak ratio for $998 \mathrm{~cm}^{-1} / 972 \mathrm{~cm}^{-1}$ as shown in Figure 6. The left area corresponds to non-heat sealed part and the right area corresponds to heat sealed part in each image in Figure 8. From the result, light color corresponds to the higher crystallinity area. In non-heat sealed part, crystallinity was increased with increasing the stabilization temperature so that the color variation is consistent with the molecular orientation of PP film. Because drawn film could raise the creep relaxation without heat stabilization after drawing. Therefore, crystallinity of non-heat sealed part of PP film was decreased 


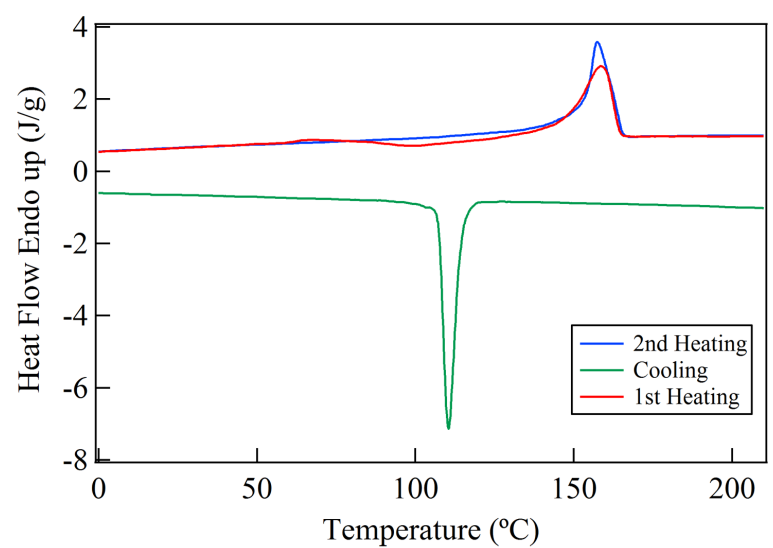

(a)

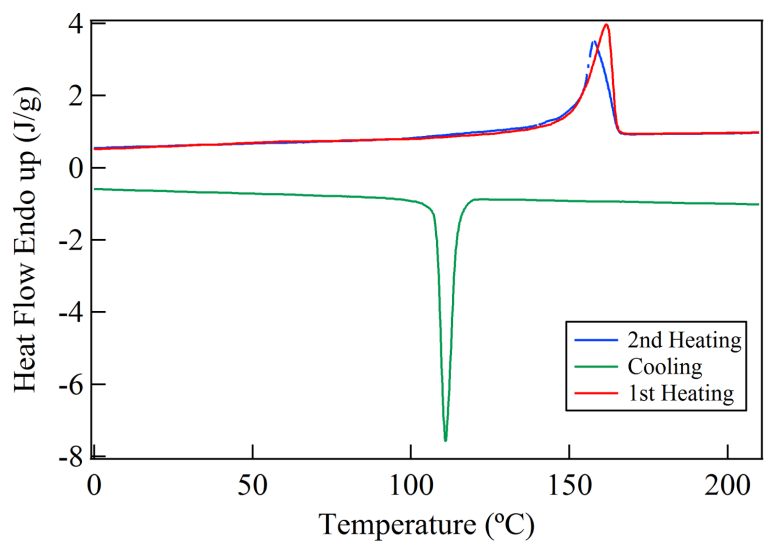

(b)

Figure 4. Typically DSC curves of (a) CPP film and (b) $2.5 \times$ drawn film at $145^{\circ} \mathrm{C}$ heat sealed temperature.

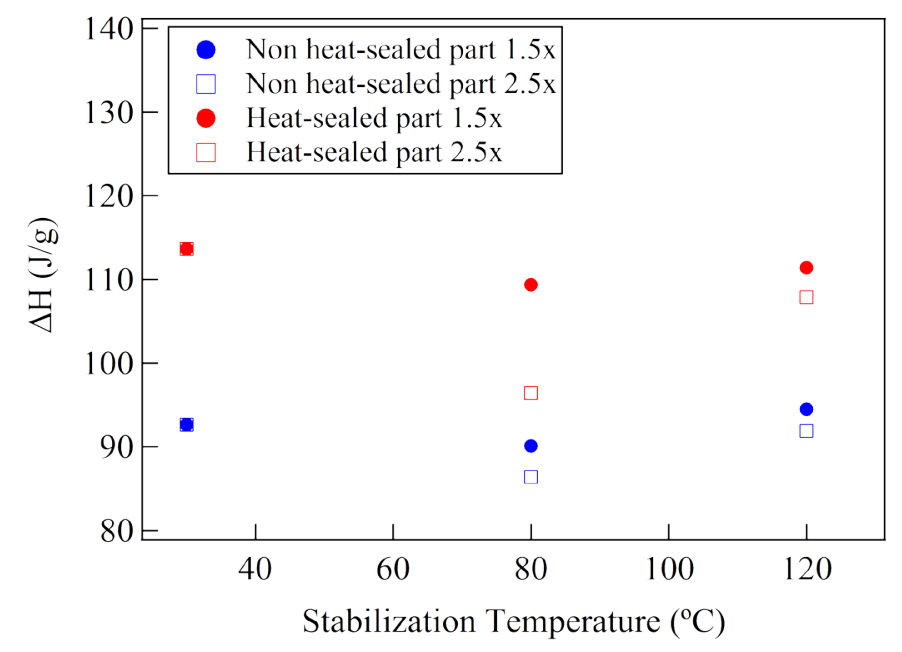

Figure 5. $\Delta \mathrm{H}$ of various heat sealed $\mathrm{PP}$ films at $145^{\circ} \mathrm{C}$ for each stabilization temperature.

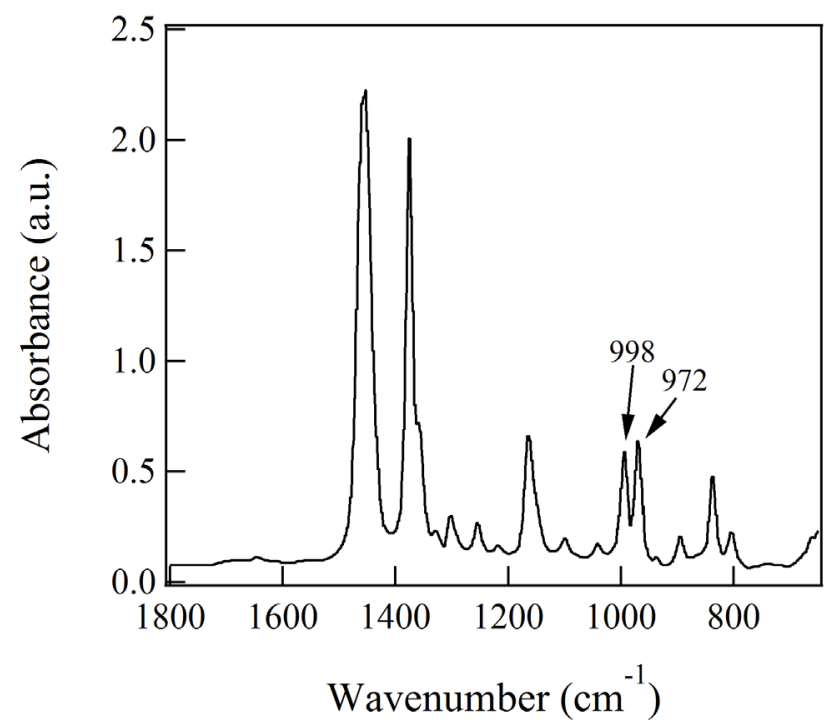

Figure 6. Typical FT-IR spectrum of PP films. 


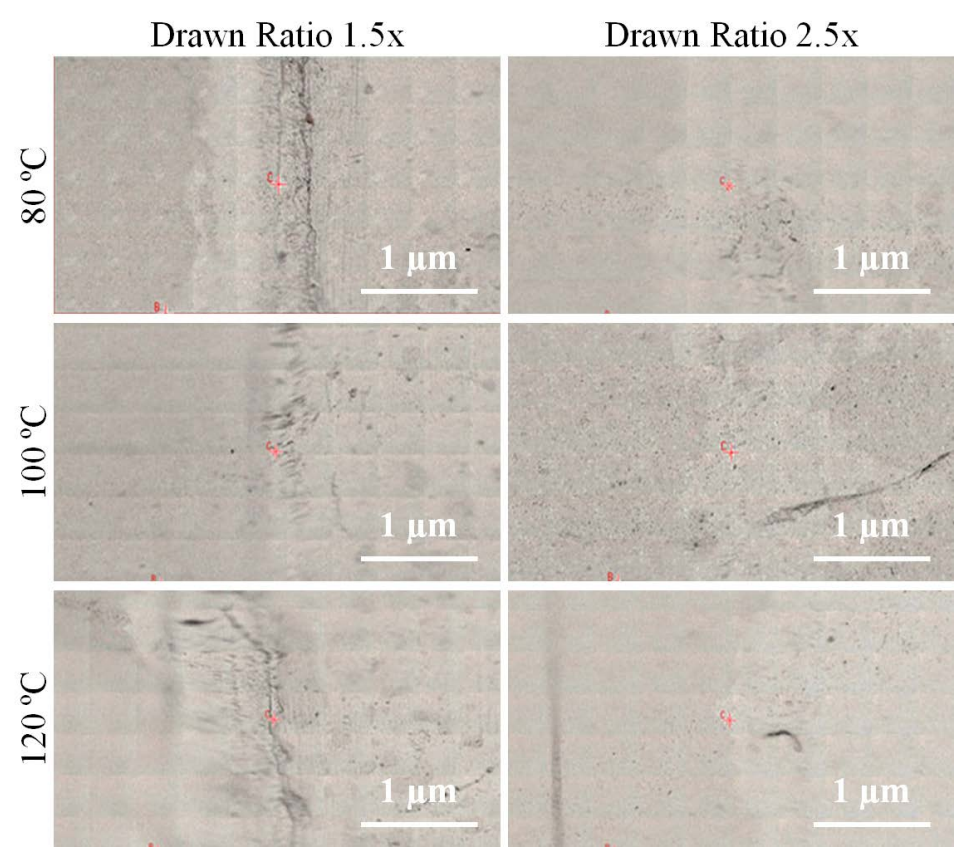

Figure 7. CCD images for PP films with drawn ratio $1.5 \times$ and $2.5 \times$, heat sealing temperature $145^{\circ} \mathrm{C}$.

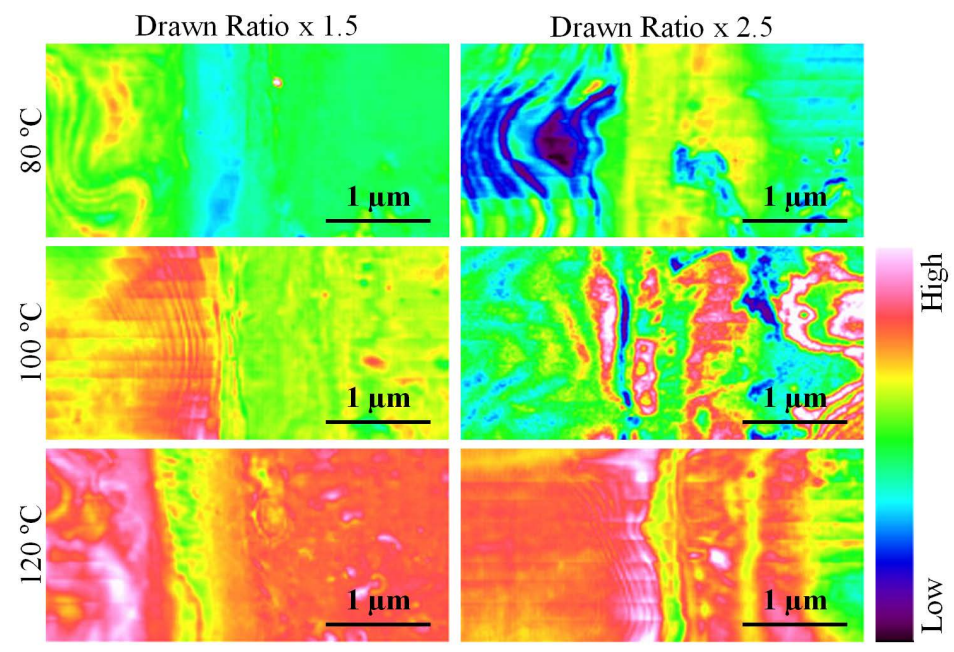

Figure 8. IR mapping results for PP films with drawn ratio $1.5 \times$ and $2.5 \times$, heat sealing temperature $145^{\circ} \mathrm{C}$.

with decreasing the stabilization temperature. On the other hand, similar tendency was shown in the heat sealed part of PP film, that is, crystallinity of heat sealed part was increased with increasing the stabilization temperature. However, in this case, it was seen that each crystallinity was lower as compared with non-heat sealed part. Because it is considered that the thermal energy of heat sealing is used for the relaxation of molecular orientation in PP films. As a result, the crystallinity of heat sealed part is lower than non-heat sealed part. In addition, the crystallinity of the edge part of heat sealing indicated the different tendency as compared with heat sealed and non-heat sealed part. It is very interesting and important phenomena of heat sealed films.

\subsection{Microscopic Raman Spectroscopy}

Figure 9 presents the Raman spectra of PP film for each drawn film. After drawing, some peaks were suppressed, where is considered that these peaks are corresponding to molecular orientation in PP films. In this 
study, the peak ratio $\left(\mathrm{I}_{848} / \mathrm{I}_{818}\right)$ was calculated in order to evaluate molecular orientation and/or crystallization changes near heat sealed edge part, and then the result was plotted in Figure 10. The peak ratio of neat film was higher than heat sealed part in Figure 10(a). The slope of strength change was observed in the interface area within $200 \mu \mathrm{m}$. As the resolution and the pitch width of microscopic Raman spectroscopy are $1 \mu \mathrm{m}$ and $1 \mu \mathrm{m}$ respectively, it was found that the molecular orientation of PP films indicated the relaxation over an appreciable range of the slope gradually. It should be noted that when this slope is rapidly steep, stress concentration will arise at this edge part for tensile loading. In Figure 10(b), the difference of Raman intensity was not indicated for each stabilization temperature, although the intensity at stabilization temperature $120^{\circ} \mathrm{C}$ became slightly coarse because of the relaxation of molecular orientation by the heat sealing energy. However, the degree of relaxation for $2.5 \times$ drawn film is very little as compared with $1.5 \times$ drawn film, and the heat sealing energy of $1.0 \mathrm{~s}$ and $145^{\circ} \mathrm{C}$ is insufficient to relax the molecular orientation of $2.5 \times$ film. As a result, it is clarified that the peel strength of the film indicated the low value as shown in Figure 3.

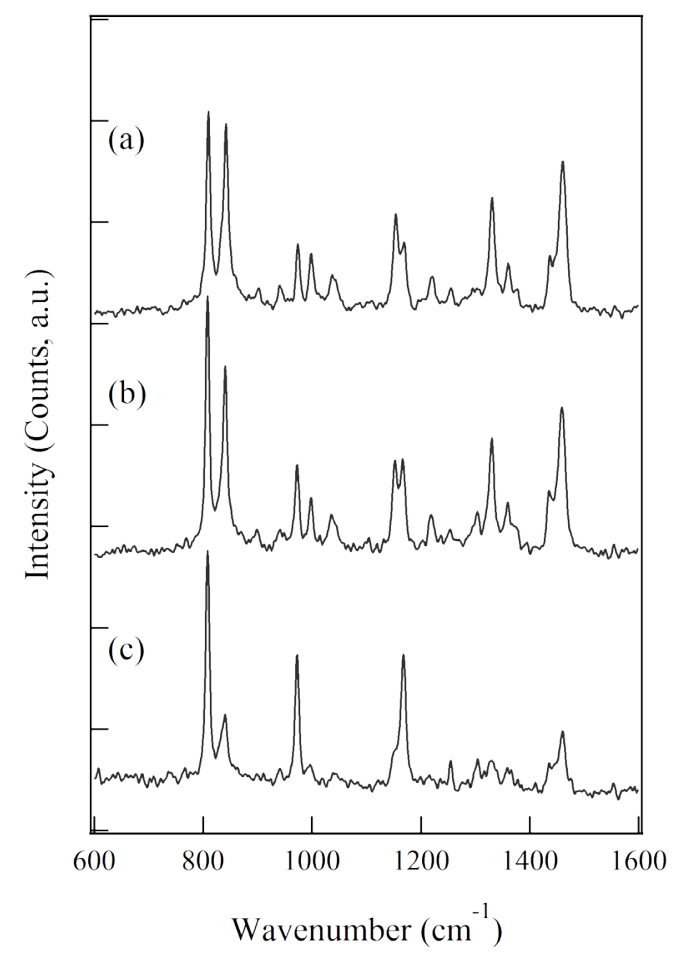

Figure 9. Typical Raman spectra of PP films with drawn ratio (a) 1.0×; (b) 1.5×; and (c) 2.5×.

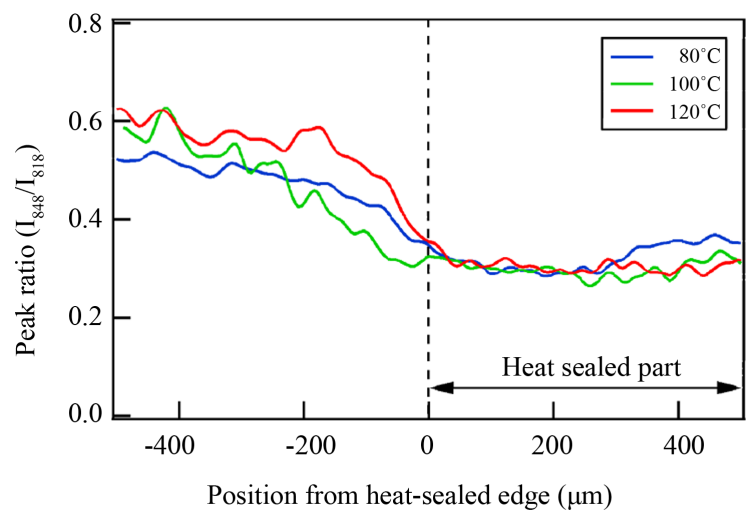

(a)

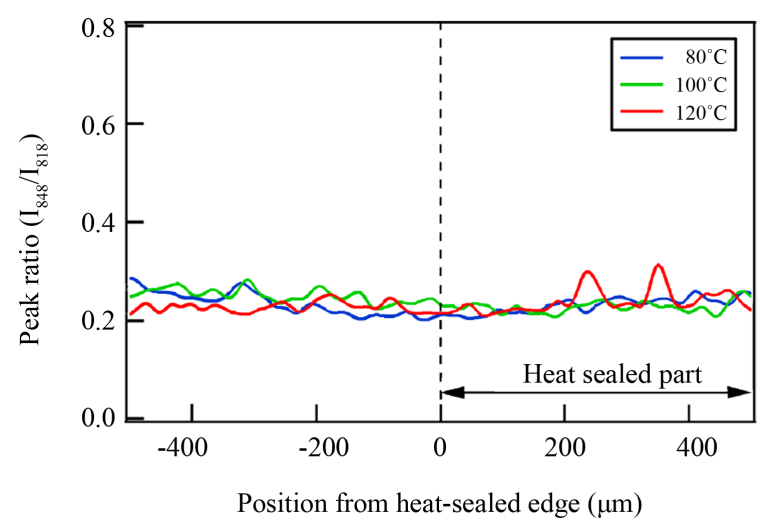

(b)

Figure 10. Raman line-mapping results for heat sealed films with drawn ratio (a) $1.5 \times$ and (b) $2.5 \times$. 


\section{Conclusion}

In this investigation, we investigated the effect of molecular orientation at heat sealed part of drawn PP film using T-peel test, DSC, micro-FT-IR, and micro-Raman spectroscopy. From these results, it was found that the peel strength was decreased with increasing the drawn ratio and stabilization temperature of PP films. In addition, the difference of $\Delta \mathrm{H}$ and melting point from the result of DSC measurement were exhibited for $1.5 \times$ drawn ratio film as compared with $2.5 \times$ one. The reason why higher drawn film indicates the poor peel strength and low thermal changes was revealed the molecular orientation and relaxation of PP films by using FT-IR imaging technique and micro-Raman spectroscopy. It was suggested that we could analyze the very small area and changes on the basis of the results of heat sealed part using micro-FT-IR and micro-Raman spectroscopy imaging, which applied for drawn PP films. In the future, it was expected that the effect of heat sealing temperature, heat sealing pressure, kinds of film, and film thickness would be investigated at the heat sealed edge part in order to get the better packaging products.

\section{References}

[1] Hashimoto, Y., Ishiaku, U.S., Leong, Y.W., Hamada, H. and Tsujii, T. (2006) Effect of Heat-Sealing Temperature on the Failure Criteria of Oriented Polypropylene/Cast Polypropylene Heat Seal. Polymer Engineering \& Science, 46, 205-214. http://dx.doi.org/10.1002/pen.20452

[2] Aithani, D., Lockhart, H., Auras, R. and Tanprasert, K. (2006) Heat Sealing Measurement by an Innovative Technique. Packaging Technology and Science, 19, 245-257. http://dx.doi.org/10.1002/pts.728

[3] Tetsuya, T., Hashimoto, Y., Ishiaku, U.S., Mizoguchi, M., Leong, Y.W. and Hamada, H. (2006) Effect of Heat-Sealing Temperature on the Properties of OPP/CPP Heat Seals. Part II. Crystallinity and Thermomechanical Properties. Journal of Applied Polymer Science, 99, 513-519. http://dx.doi.org/10.1002/app.22443

[4] Farris, S., Cozzolino, C.A., Introzzi, L. and Piergiovanni, L. (2009) Effects of Different Sealing Conditions on the Seal Strength of Polypropylene Films Coated with a Bio-Based Thin Layer. Packaging Technology and Science, 22, 359369. http://dx.doi.org/10.1002/pts.861

[5] Tetsuya, T., Ishiaku, U.S., Mizoguchi, M. and Hamada, H. (2005) The Effect of Heat Sealing Temperature on the Properties of OPP/CPP Heat Seal. I. Mechanical Properties. Journal of Applied Polymer Science, 97, 753-760. http://dx.doi.org/10.1002/app.21320

[6] Yuan, C.S., Hassan, A., Ghazali, M.I.H. and Ismail, A.F. (2007) Heat Sealability of Laminated Films with LLDPE and LDPE as the Sealant Materials in Bar Sealing Application. Journal of Applied Polymer Science, 104, 3736-3745. http://dx.doi.org/10.1002/app.25863

[7] Mihindukulasuriya, S.D. and Lim, L.-T. (2013) Heat Sealing of LLDPE Films: Heat Transfer Modeling with Liquid Presence at Film-Film Interface. Journal of Food Engineering, 116, 532-540. http://dx.doi.org/10.1016/j.jfoodeng.2012.12.027

[8] Planes, E., Marouani, S. and Flandin, L. (2011) Optimizing the Heat Sealing Parameters of Multilayers Polymeric Films. Journal of Materials Science, 46, 5948-5958. http://dx.doi.org/10.1007/s10853-011-5550-4

[9] Yamada, K., Miyata, K., Konishi, R., Tsujii, T. and Hashimoto, Y. (2015) Heat Seal Processing by Using Various Seal Bar Shape. AIP Conference Proceedings, 1664, 080002-1-080002-5. http://dx.doi.org/10.1063/1.4918458

[10] Sadeghi, F., Ajji, A. and Carreau, P.J. (2007) Analysis of Row Nucleated Lamellar Morphology of Polypropylene Obtained from the Cast Film Process: Effect of Melt Rheology and Process Conditions. Polymer Engineering \& Science, 47, 1170-1178. http://dx.doi.org/10.1002/pen.20837

[11] Cole, K.C., Perrin-Sarazin, F. and Dorval-Douville, G. (2005) Infrared Spectroscopic Characterization of Polymer and Clay Platelet Orientation in Blown Films Based on Polypropylene-Clay Nanocomposite. Macromolecular Symposia, 230, 1-10. http://dx.doi.org/10.1002/masy.200551135 